University of Nebraska - Lincoln

DigitalCommons@University of Nebraska - Lincoln

Roger Kirby Publications

Research Papers in Physics and Astronomy

May 1994

Low-temperature characterization of the magnetic properties of MnBiAl thin films

Kurt W. Wierman

University of Nebraska - Lincoln

J. X. Shen

University of Nebraska - Lincoln

Roger D. Kirby

University of Nebraska-Lincoln, rkirby1@unl.edu

David J. Sellmyer

University of Nebraska-Lincoln, dsellmyer@unl.edu

Follow this and additional works at: https://digitalcommons.unl.edu/physics_kirby

Part of the Physics Commons

Wierman, Kurt W.; Shen, J. X.; Kirby, Roger D.; and Sellmyer, David J., "Low-temperature characterization of the magnetic properties of MnBiAl thin films" (1994). Roger Kirby Publications. 19.

https://digitalcommons.unl.edu/physics_kirby/19

This Article is brought to you for free and open access by the Research Papers in Physics and Astronomy at DigitalCommons@University of Nebraska - Lincoln. It has been accepted for inclusion in Roger Kirby Publications by an authorized administrator of DigitalCommons@University of Nebraska - Lincoln. 


\title{
Low-temperature characterization of the magnetic properties of MnBiAl thin films
}

\author{
K. W. Wierman, J. X. Shen, R. D. Kirby, and D. J. Sellmyer \\ Behlen Laboratory of Physics and Center for Materials Research and Analysis, University of Nebraska, \\ Lincoln, Nebraska 68588-0111
}

The magnetic properties of thin-film samples of $\mathrm{MnBi}_{0.8} \mathrm{Al}_{x}$ with aluminum concentrations of $x=0.0,0.4,0.6$, and 0.8 were systematically studied over a temperature range of 20 to $300 \mathrm{~K}$. The as-deposited films are amorphous and nonmagnetic, but highly textured polycrystalline films that are ferromagnetic are formed by annealing at $350{ }^{\circ} \mathrm{C}$. Our measurements show that the coercivity of such films rapidly decreases, then approaches a constant value $(4 \mathrm{kOe}$ for $x=0.4)$ with increasing annealing time. Magnetic measurements show that both anisotropy and coercivity decrease with decreasing temperature. Unlike bulk $\mathrm{MnBi}$, our $\mathrm{MnBi}_{0.8} \mathrm{Al}_{x}$ thin films do not have a spin reorientation transition at low temperatures. This may be due to impediment of the lattice contraction by the $\mathrm{Al}$ atoms doped into the interstitial sites of the $\mathrm{MnBi}$ lattice.

\section{INTRODUCTION}

MnBiAl has been proposed as a possible magnetooptical storage candidate due to its large Kerr rotation and perpendicular magnetic anisotropy. Wang reported that (Al,Si) doping increased the Kerr rotation, improved the thermal stability, and reduced the polycrystalline grain size. ${ }^{1}$ Roberts ${ }^{2}$ carried out neutron diffraction studies on bulk $\mathrm{MnBi}$ and found that the $c$ axis contracted by more than $1 \%$ as the temperature was lowered from 300 to $5 \mathrm{~K}$. Recent work by Guo et al. ${ }^{3}$ on bulk MnBi showed that the uniaxial anisotropy constant decreases substantially with decreasing temperature, and the lattice contraction may be a major contributing factor to this decrease. It is also of interest to ascertain what role aluminum doping plays in determining the anisotropy energy and its temperature dependence.

\section{EXPERIMENT}

$\mathrm{MnBi}_{0,8} \mathrm{Al}_{x}$ thin films with nominal Al contents $x=0.0$, $0.4,0.6$, and 0.8 were made by sequential evaporation of $B \mathrm{i}$, $\mathrm{Mn}$, and $\mathrm{Al}$ from a tungsten boat onto a room-temperature glass substrate. The base pressure of the vacuum chamber was $3 \times 10^{-7}$ Torr, and the film thickness was typically 80 $\mathrm{nm}$. After evaporation, the thin films were covered with a 150-nm-thick $\mathrm{SiO}_{x}$ protective layer. Samples were annealed in vacuum for $4 \mathrm{~h}$ at $350^{\circ} \mathrm{C}$. X-ray diffraction measurements show large intensities for the (002) and (004) $\mathrm{MnBi}$ peaks, indicating that the annealed films have the NiAs-type hexagonal structure with the $c$ axis highly oriented along the film normal. The $c$-axis lattice parameter of $\mathrm{MnBi}_{0.8} \mathrm{Al}_{0.8}$ $(6.06 \AA)$ is the same as that of $\mathrm{MnBi}_{0.8}(6.07 \AA)$ within measurement error, similar results were obtained for $x=0.4$, 0.6 . In the measurements reported here, the temperature dependencies of the perpendicular anisotropy constant $K_{u}$, coercive force $H_{c}$, and remnant magnetization were determined from hysteresis loops generated by an alternatinggradient force magnetometer (AGFM). Kerr rotation versus total annealing time measurements were made using an apparatus described elsewhere. ${ }^{4}$

\section{RESULTS AND DISCUSSION}

Figure 1 shows the perpendicular and parallel hysteresis loops as measured with the AGFM for $\mathrm{MnBi}_{0.8} \mathrm{Al}_{0.4}$ at three different temperatures. These loops clearly show that perpendicular anisotropy is maintained down to low temperatures for $x=0.4$, and similar loops were obtained for the $x=0.0$, 0.6 , and 0.8 samples. No evidence of the spin reorientation transition reported for bulk $\mathrm{MnBi}$ is found in these measurements. ${ }^{5}$

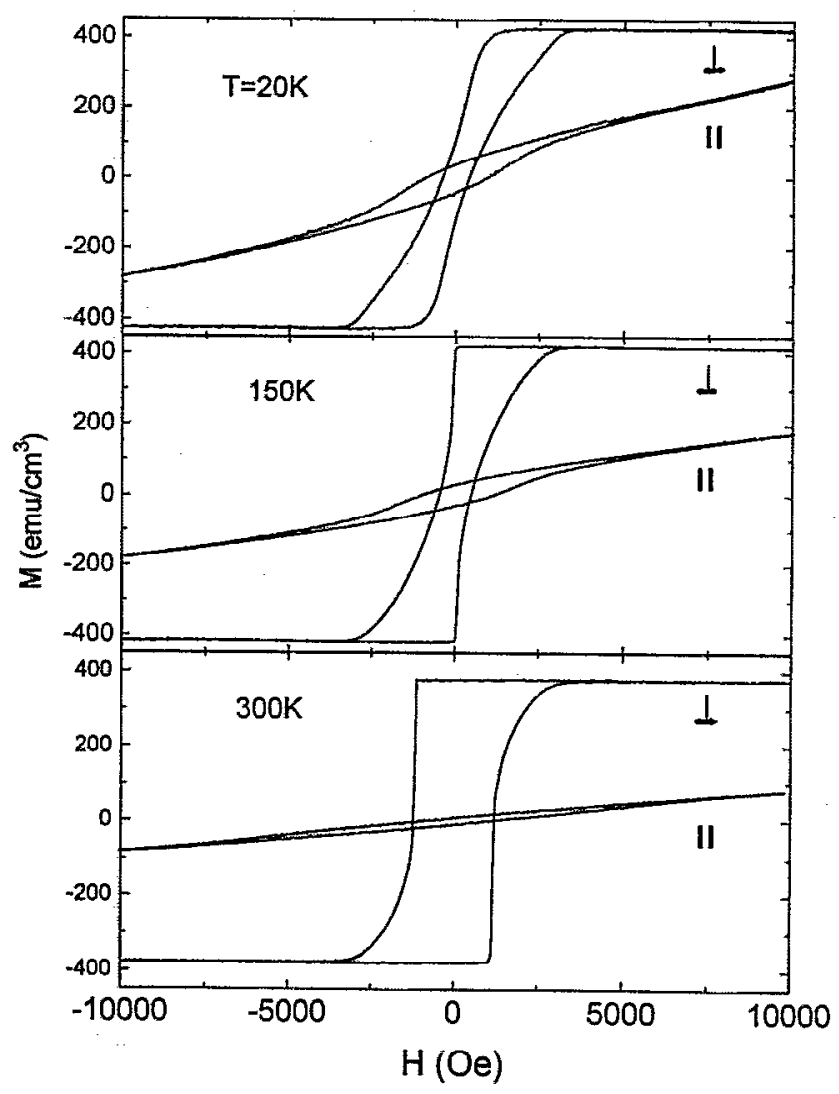

FIG. 1. Parallel and perpendicular magnetization loops for $\mathrm{MnBi}_{0.8} \mathrm{Al}_{0.4}$. The parallel and perpendicular loops are indicated. 


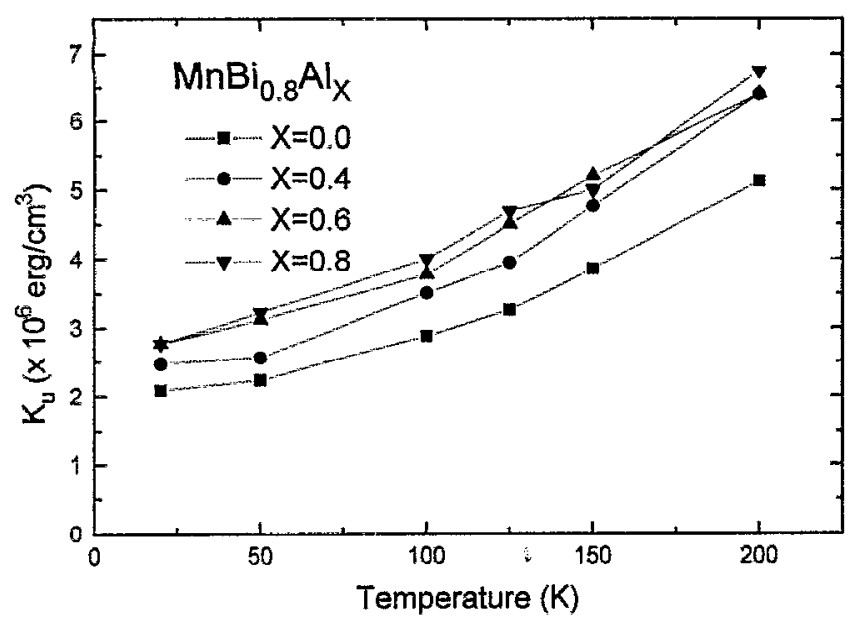

FIG. 2. Temperature dependence of the anisotropy constant $K_{u}$ of $\mathrm{MnBi}_{48,} \mathrm{Al}_{1,4}$ for four different sumple compositions.

The area between the perpendicular and parallel hysteresis loops was used to determine the magnetic anisotropy constant $K_{u}$, and Fig. 2 shows the temperature dependence of $K_{u}$ for $x=0.0,0.4,0.6$, and 0.8 . It can be seen that for each sample $K_{u}$ increases with increasing temperature, as was found for bulk $\mathrm{MnBi},{ }^{3,5}$ with the $x=0.8$ sample showing the largest increase. $K_{u}$ could not be reliably determined for temperatures above $200 \mathrm{~K}$ because of the limited magnetic field available on the AGFM. Assuming the decrease in $K_{u}$ with decreasing temperature is due to contraction of the $c$ axis, theu $\mathrm{Al}$ doping appears to hinder this contraction. This would be consistent with the $\mathrm{Al}$ atoms residing at the interstitial sites as opposed to in the grain boundaries.

Figure 3 plots the ratio of the remnant magnetization to the saturation magnetization $\left(M_{r} / M_{s}\right)$ as a function temperature. The sharp drop in this ratio as $T$ goes below $150 \mathrm{~K}$ is likely associated with the rapid reduction in $K_{u}$ as the temperature is lowered. However, even at $50 \mathrm{~K}$ the anisotropy field $\left(2 K_{u} / M_{s}\right)$ is still a factor of two to three larger than the demagnetizing field $\left(H_{d}=4 \pi M_{s}\right)$, suggesting that the rapid

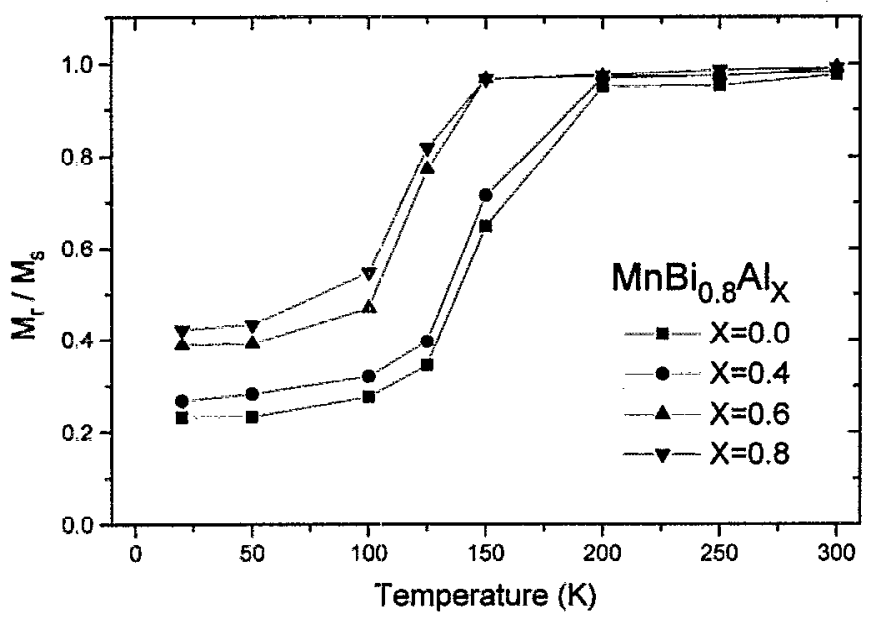

FIG. 3. Temperature dependence of the remnant magnetization $M_{r}$ for four different sample compositions.

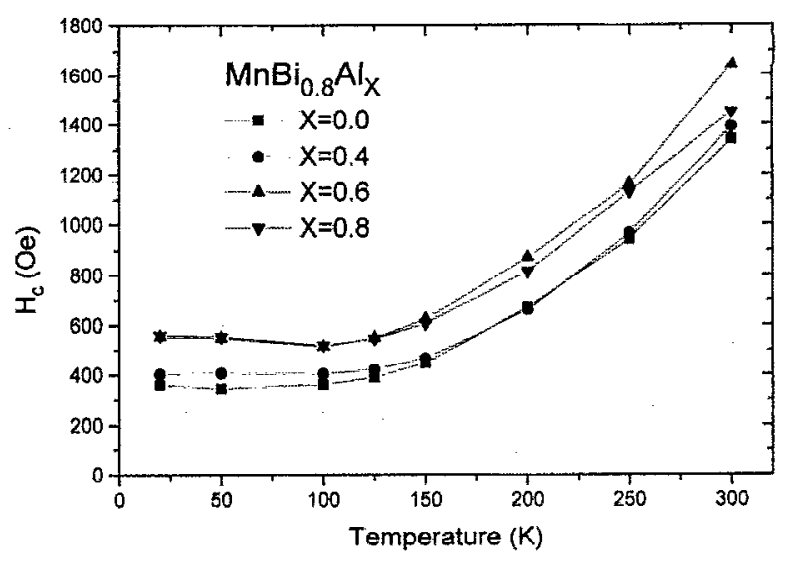

FIG. 4. Coercivity of $\mathrm{MnBi}_{0.8} \mathrm{Al}_{0.4}$ vs temperature for four different sample compositions.

drop in the remnant magnetization near $150 \mathrm{~K}$ is due to domain formation. It should also be noted that $\mathrm{Al}$ doping seems to only moderately improve loop squareness.

Figure 4 shows the coercivity as a function of temperature for all four samples. It should be noted that the $x=0.8$ sample has a slightly smaller coercivity than the $x=0.6$ at $300 \mathrm{~K}$, even though it has a larger value of $K_{u}$. This suggests that physical properties other than the anisotropy field, such as crystalline microstructure and small variations in composition, are important in determining the magnitude of the coercivity.

Figure 5 shows the coercivities of $\mathrm{MnBi}_{0.8}$ and $\mathrm{MnBi}_{0.8} \mathrm{Al}_{x}$ as a function of annealing time at $350{ }^{\circ} \mathrm{C}$. The initial rapid decreases in the coercivities are consistent with crystallization of small particles, followed by growth of the particles. After annealing for about $6 \mathrm{~h}$, no additional reductions in the coercivities are observed, suggesting that the crystallization process is completed and the particle sizes have reached their maximum values. The magnitude of the Kerr rotation (not shown) shows a behavior consistent with this interpretation. It rises rapidly from zero as a function of annealing time, finally saturating after $6 \mathrm{~h}$ of annealing. The

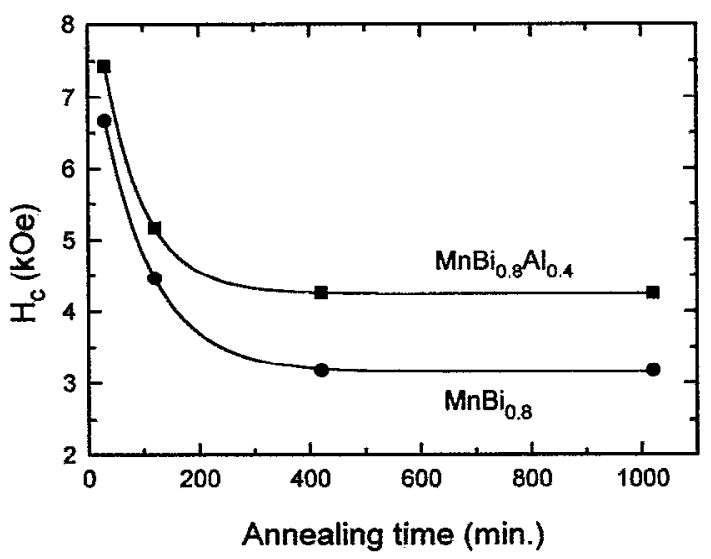

FIG. 5. Coercivity vs annealing time for $\mathrm{MnBi}_{0.8} \mathrm{Al}_{0.4}$ and $\mathrm{MnBi}_{0.8}$. 


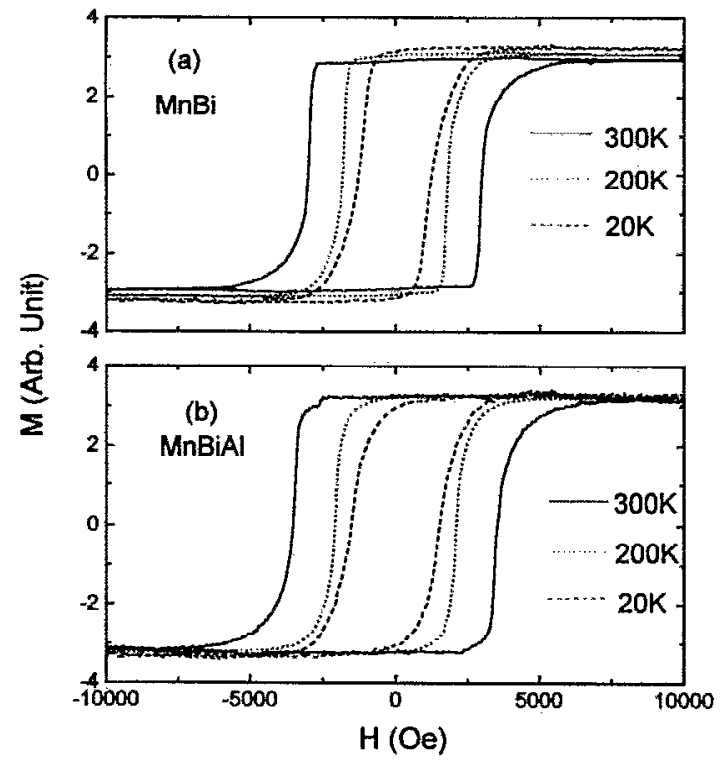

FIG. 6. Hysteresis loops obtained with an AGFM for (a) $\mathrm{MnBi}_{0.8}$ and (b) $\mathrm{MnBi}_{0,8} \mathrm{Al}_{0,4}$ after $45 \mathrm{~h}$ of annealing at $350^{\circ} \mathrm{C}$.

Al-doped sample has a larger coercivity for all annealing times, which may be a reflection of the smaller grain sizes expected with Al doping. ${ }^{1}$

Figure 6 shows the temperature dependencies of the hysteresis loops for $\mathrm{MnBi}_{0.8}$ and $\mathrm{MnBi}_{0.8} \mathrm{Al}_{0.4}$ after $45 \mathrm{~h}$ of annealing. Notice that both samples have nearly $100 \%$ remnant magnetization, even at the lowest temperature of $20 \mathrm{~K}$. These results show that annealing conditions can have a larger effect on the remnant magnetization than does Al doping. The similar results here for $\mathrm{MnBi}_{0.8}$ and $\mathrm{MnBi}_{0.8} \mathrm{Al}_{0.4}$ may be a consequence of diffusion of $\mathrm{Si}$ from the $\mathrm{SiO}_{x}$ overcoat into the bulk of the sample, as has been suggested by Wang. ${ }^{1}$

In summary, we have studied the magnetic properties of $\mathrm{MnBi}_{0.8} \mathrm{Al}_{x}$ for four different compositions over the temperature range 20 to $300 \mathrm{~K}$. The values of the uniaxial anisotropy constant $K_{u}$ were found to increase with Al content at room temperature and below. Our measurements showed no evidence of the low-temperature spin-reorientation transition previously observed in bulk $\mathrm{MnBi}$. Coercivity measurements versus annealing time were obtained showing the sensitivity of the magnetic properties to annealing conditions. Further $x$-ray diffraction and electron microscopy studies are needed to determine the positions of the $\mathrm{Al}$ atoms and further to determine the effects that annealing conditions have on the crystal structure and microstructure. These studies are under way.

\section{ACKNOWLEDGMENTS}

We are indebted for financial support of this work to the National Science Foundation under Grant No. DMR9222976, and to the Advanced Research Projects Agency/ National Storage Industry Consortium under Grant No. MDA972-93-1-0009.

${ }^{1}$ Y. J. Wang, J. Magn. Magn, Mater. 84, 39 (1990).

${ }^{2}$ B. W. Roberts, Phys. Rev. 104, 607 (1956).

${ }^{3}$ X. Guo, X. Chen, Z. Altounian, and J. O. Ström-Olsen, Phys. Rev. B 46, 14578 (1992).

${ }^{4}$ J. X. Shen, R. D. Kirby, and D. J. Sellmyer, J. Magn. Magn. Mater. 81, 107 (1989).

${ }^{5}$ R. S. Tebble and D. J. Craik, Magnetic Materials (Wiley-Interscience, New York, 1969), p. 125. 